\title{
Anti-inflammatory Interventional Strategies to Promote Islet Transplantation Outcomes
}

Preeti Chhabra, Daniel Bowers, Linda Langman, Arazdordi Toumadje and Kenneth L. Brayman

Department of Surgery, University of Virginia, Charlottesville, VA 22908, USA

*Corresponding author: Kenneth L. Brayman, Department of Surgery, University of Virginia School of Medicine, P.O. Box 800709, Charlottesville, VA 22908-0709, USA, Tel: 434-924-9370; Fax: 434-924-5539, E-mail: klb9r@hscmail.mcc.virginia.edu

Rec date: Aug 7, 2014; Acc date: Aug 7, 2014; Pub date: Aug 9, 2014

Copyright: ( 2014 Chhabra P, et al. This is an open-access article distributed under the terms of the Creative Commons Attribution License, which permits unrestricted use, distribution, and reproduction in any medium, provided the original author and source are credited.

\section{Editorial}

While exogenous insulin therapy remains the most common and effective standard for day-to-day control of Type 1 Diabetes (T1D), recurring incidences of hypoglycemic episodes and long-term complications such as retinopathy, neuropathy, nephropathy, and cerebrovascular/cardiovascular diseases necessitate transplantation of either whole pancreas or pancreatic islets as a more effective treatment in a high percentage of patients [1-6]. Of the two, clinical islet transplantation is less invasive, being associated with a $20 \%$ lower morbidity risk compared to whole pancreas transplantation. At the same time, it offers substantial benefits in terms of lowering daily insulin requirement, improving levels of glycated hemoglobin (HbA1c), reducing incidences of debilitating hypoglycemic episodes and unawareness, and affording potential insulin independence. However, widespread applicability of the procedure is mainly hindered by an inadequate supply of donor pancreata, graft rejection, recurrence of autoimmunity, deleterious side-effects associated with chronic immune-suppression, and last but not least, financial considerations [1].

Several clinical trials have demonstrated a gradual attrition of allograft function overtime, with insulin independence frequently being lost by the fifth year of follow-up. Factors contributing to the eventual decline in graft function and survival include, amongst others, a) innate non-specific inflammatory reactions in the microenvironment of the graft during the peritransplant period that mediate early loss of nearly $50 \%$ of the transplanted islets; b) ischemiareperfusion injury (IRI) following transplantation; c) relative hypoxia and poor vascularization of islets resulting in inefficient engraftment and primary dysfunction of islets, d) progressive destruction of the graft by innate and adaptive immune mechanisms and the recurrence of autoimmunity; e) metabolic distress from exhaustion of a marginal $\beta$-cell mass and f) drug toxicity associated with immunosuppressive regimens $[1,7]$. The detrimental effects of the instant blood mediated inflammatory reaction (IBMIR) as well as IRI-induced inflammation contribute to peritransplant loss of a significant proportion of transplanted islet mass, likely promoting alloantigen presentation and accelerating subsequent cell-mediated allogeneic immune responsiveness [7-9]. Therefore, the discovery of novel antiinflammatory pharmacologic agents or strategies that can be inducted into standard immunosuppressive regimens to effectively inhibit inflammatory cascades in the period immediately following transplantation will significantly impact longitudinal clinical islet transplant outcomes. To this end, numerous preclinical studies using selective adenosine $\mathrm{A} 2 \mathrm{~A}$ receptor (A2AR) agonists, antagonists, A2AR knockout as well as chimeric mice have suggested the therapeutic potential of A2AR agonists for the treatment of ischemia reperfusion injury (IRI) and promoting graft survival outcomes [9]. Activation of adenosine $\mathrm{A} 2 \mathrm{~A}$ receptors (A2AR) reduces inflammation by inhibiting the activation of pro-inflammatory cells, decreasing endothelial adhesion molecule expression and reducing the release of proinflammatory cytokine mediators [7,9]. Our studies conducted in both the murine sub-kidney capsule as well as the clinically-relevant hepatic intra-portal islet transplantation models indicate that infusion of A2AR agonist ATL146e and ATL313 in diabetic recipient mice during the peritransplant period resulted in reduction of both, inflammation-mediated early loss of a minimal dose islet graft as well as in the time taken to achieve sustained normoglycemia [7]. No significant improvement in time taken to achieve normoglycemia was observed between diabetic A2AR knockout (A2AR-/-) recipients of congenic C57BL/6 islets with or without administration of ATL146e therapy. In histological studies, A2AR agonist treatment demonstrated marked reductions in neutrophils and lymphocyte infiltration, cellular necrosis and fibrosis, as well as in the size and number of lymphoid nodules. In vitro studies indicated that islets incubated with A2AR agonists remained viable and functional. Co-culture of islets with leukocytes followed by glucose stimulated islet secretion (GSIS) challenge demonstrated an inhibition of islet stimulation index that was subsequently restored upon addition of ATL146e. Furthermore, this beneficial effect was blocked by addition of the A2AR selective antagonist SCH58261 indicating that ATL/A2AR binding on inflammatory cells inhibited inflammation-mediated islet cell damage and dysfunction. This was supported by the observed failure of ATL146e to preserve insulin secretion function of islets co-cultured with A2AR-/- leukocytes. Therefore, these results indicate that in islet transplant protocols designed to minimize systemic immunosuppression, including a short course of an A2AAR agonist as part of induction therapy could reduce early peritransplant islet loss, thereby improving islet graft outcomes. Additionally, by reducing the number of islets required for successful clinical islet transplantation, a greater efficiency in the use of human islets for clinical transplantation would increase the availability of this procedure to a greater number of potential recipients.

We are also focused on the role of polyclonal serum Immunoglobulin $\mathrm{M}$ (IgM) antibodies in preventing the onset and progression of T1D, preventing the recurrence of autoimmunity as well as in promoting islet graft survival [10-11]. Elevated levels of IgM antileukocyte autoantibodies (IgM-ALAs) have been associated with lower incidence and severity of acute human heart and kidney graft rejections, thus permitting better graft survival. Our studies indicate that polyclonal serum IgM therapy with minimal dose islet transplantation promotes both syngeneic and allogeneic islet graft survival and may prove to be an important adjunctive therapy to advance successful islet engraftment and transplant outcomes. 
Citation: Chhabra P, Bowers D, Langman L, Toumadje A, Brayman KL (2014) Anti-inflammatory Interventional Strategies to Promote Islet Transplantation Outcomes. Surgery Curr Res 4: e116. doi:10.4172/2161-1076.1000e116

Page 2 of 2

In conclusion, our studies indicate that A2AR agonist therapy or polyclonal serum IgM therapy reduces inflammation-mediated islet cell loss following transplantation, thereby allowing for an accelerated rate of cure with marginal donor islets. Including a short course of either as part of the induction therapy in immunosuppressive regimens would increase both, the efficacy of the procedure in terms of improved long term islet transplantation outcomes as well as the availability of the procedure to a larger number of diabetic recipients.

\section{References}

1. Chhabra P, Brayman KL (2014) Overcoming barriers in clinical islet transplantation: current limitations and future prospects. Curr Probl Surg 51: 49-86.

2. Jahansouz C1, Kumer SC, Ellenbogen M, Brayman KL (2011) Evolution of $\hat{\mathrm{I}}^{2}$-Cell Replacement Therapy in Diabetes Mellitus: Pancreas Transplantation. Diabetes Technol Ther 13: 395-418.

3. Ramesh A Chhabra P, Brayman KL (2013) Pancreatic islet transplantation in type 1 diabetes mellitus: an update on recent developments. Curr Diabetes Rev 9: 294-311.

4. Chhabra P, Brayman KL (2011) Current status of immunomodulatory and cellular therapies in preclinical and clinical islet transplantation. J Transplant 2011: 637692.
5. Jahansouz C, Jahansouz C, Kumer SC, Brayman KL (2011) Evolution of BCell Replacement Therapy in Diabetes Mellitus: Islet Cell Transplantation. J Transplant.

6. Huang X, Moore DJ, Ketchum RJ, Nunemaker CS, Kovatchev B, et al. (2008) Resolving the conundrum of islet transplantation by linking metabolic dysregulation, inflammation, and immune regulation. Endocr Rev 29: 603-630.

7. Chhabra P, Wang K, Zeng Q, Jecmenica M, Langman L, et al. (2010) Adenosine $\mathrm{A}(2 \mathrm{~A})$ agonist administration improves islet transplant outcome: Evidence for the role of innate immunity in islet graft rejection. Cell Transplant 19: 597-612.

8. Nilsson B, Ekdahl KN, Korsgren O (2011) Control of instant bloodmediated inflammatory reaction to improve islets of Langerhans engraftment. Curr Opin Organ Transplant 16: 620-626.

9. Chhabra P, Linden J, Lobo P, Douglas Okusa M, Lewis Brayman K (2012) The immunosuppressive role of adenosine $\mathrm{A} 2 \mathrm{~A}$ receptors in ischemia reperfusion injury and islet transplantation. Curr Diabetes Rev 8: 419-433.

10. Chhabra P, Schlegel K, Okusa MD, Lobo PI, Brayman KL (2012) Naturally occurring immunoglobulin $\mathrm{M}$ (nIgM) autoantibodies prevent autoimmune diabetes and mitigate inflammation after transplantation. Ann Surg 256: 634-641.

11. Lobo PI, Brayman KL, Okusa MD (2014) Natural IgM anti-leucocyte autoantibodies (IgM-ALA) regulate inflammation induced by innate and adaptive immune mechanisms. J Clin Immunol 34 Suppl 1: S22-29. 